\title{
THE EFFECT OF ATMOSPHERIC ELECTROMAGNETIC RADIATION ON AN OPENED SYSTEM
}

\author{
Zoltán HODAI ${ }^{1}$, Dora RIPPELNÉ PETHŐ ${ }^{2}$, Géza HORVÁTH ${ }^{3}$, László HANÁK ${ }^{4}$, Róbert BOCSI ${ }^{5}$ \\ University of Pannonia, Faculty of Engineering, Institute of Chemical and Process Engineering, Veszprem, \\ Hungary \\ ${ }^{1}$ hodaiz@almos.uni-pannon.hu \\ ${ }^{2}$ pethod@almos.uni-pannon.hu \\ 3.horvathg@almos.uni-pannon.hu \\ ${ }^{4}$ hanakl@almos.uni-pannon.hu \\ ${ }^{5}$ bocsirobert@almos.uni-pannon.hu
}

\begin{abstract}
In opened systems with liquid-phase (for example open-source bioreactors for various purposes) very significant temperature can be generated. The operation of the system can be impaired, possibly completely inhibited (too low, too high temperature values). The analytic description of the operation's heat flow is needed to achieve the optimized operation and to block the thermodynamic inhibition. The aim is to examine the inner system opportunities and the auxiliary energy. The estimates values quantify the effects of atmospheric electromagnetic radiation on opened systems. Based on the developed model by increasing the complexity of the method, it is appropriate to describe the heat flow of opened systems and to explore the energy integration possibilities.
\end{abstract}

Keywords: atmospheric, electromagnetic radiation, heat flow, heat balance, opened system.

\section{Introduction}

Generally, it can be stated that the thermal streams entering into the thermodynamic system, minus the output heat flows in the operation unit, gives the amount change of heat.

Our opened system is considered to be a perfectly stirred pan (the temperature of the liquid in the vat equals the temperature of the outlet liquid flow, (1)).

$$
Q_{\text {in }}+Q_{\text {gain }}-Q_{\text {out }}-Q_{\text {loss }}=\frac{d Q_{\text {poind }}}{d t}
$$

where

$Q_{\text {in }}$ : the inlet fluid temperature [J/s],

$Q_{\text {out }}$ : the outlet heat flow [J/s],

$Q_{\text {gain }}$ : open pound initial heat flow [J/s],

$Q_{\text {loss }}$ : open pound outlet heat, heat loss [J/s],

$Q_{\text {pound }}:$ heat quantity of liquid in open pound [J].
The $Q_{\text {gair }} / Q_{\text {loss }}$ represent the heat extracted from the environment and returned to the environment, the mechanical energy inputs generated by the processes in the tank as well as the input/ output heat streams.

The definable gain:

$Q_{S}$ : shortwave radiation coming from the sun,

$Q_{M}$ : the heat by mechanical energy input (mixing, aeration)

$Q_{B}$ : biochemical exothermic, oxidation, reaction-generated heat currents.

In addition, the heat gains or losses are - depending on the circumstances - as follows:

$Q_{A}$ : Atmospheric longwave electromagnetic radiation

$Q_{F P}$ : heat flow associated with the evaporation of the free liquid surface of the pound.

$Q_{F A}$ : heat transfer temperature of the free liquid surface 
$Q_{L}: Q_{H}:$ Flux in the pound with liquid / abstract heat flow,

$Q_{F}$ is heat transfer on the walls of the pool.

\section{Electromagnetic radiation interactions}

Heat transfer is a special manifestation of heat radiation. The shortwave electromagnetic radiation coming from the sun can be taken into account without the need for completeness: the global radiation absorbed on the liquid surface of our open system can be estimated with a good approximation (2) [1]:

$$
Q_{s}=Q_{s, 0}\left(1-0,0071 C_{c}^{2}\right) A_{s z}
$$

where

$Q_{s, 0}$ specific solar radiation in the sky, heat flux density, $\left[\mathrm{W} / \mathrm{m}^{2}\right]$,

$C_{c}$ cloud cover (on scale 10 ),

$A_{s z}$ 's surface area $\left[\mathrm{m}^{2}\right]$,

$Q_{s}$ is the heat generated from absorbed global radiation [W].

\subsection{Atmospheric long-wave electromagne- tic radiation}

The heated ground surface and the liquid surface, in good approximation to their surface temperature, radiate in the infrared (longwave) range. Similarly to short-wave radiation, part of the surface long-wave radiation is absorbed or reradiated by gases and aerosol particles in the atmosphere. The absorption and emission of gases for longwave electromagnetic radiation are selective. Most of the single and double atomic gases are "transparent" for the heat rays. However, many of the three or more atomic gases absorb heat rays in certain wavebands, so they can emit in these bands. In the atmosphere of our opened system, such as gases, vapours are the following: carbon dioxide, ammonia, sulphur dioxide, water vapour [2-5].

The relationship between surface liquid longitude and surface longitude [6] can be taken from the open pound surface to outer space by the relation (3):

$$
Q_{\text {out }}=\varepsilon_{\text {liquid }} \sigma\left(T_{\text {biomass }}+273\right)^{4}
$$

where

$\varepsilon_{\text {liquid }}$ is the flow $\left(5,67 \cdot 10-8 \mathrm{~W} / \mathrm{m}^{2} / \mathrm{K}^{4}\right)$ Stefan-Boltzmann

$T_{\text {biomass }}$ is the wastewater temperature [ $\left.{ }^{\circ} \mathrm{C}\right]$ [7].

Atmospheric irradiation is a longitudinal wave from the upper airspace to the horizontal plane.
The heat flow density of liquid of the surface is (4) $[6,7]$ absorbed on its surface:

$$
Q_{\text {atm. }}=(1-\lambda) \varepsilon_{s k y} \sigma\left(T_{s k y}\right)^{4}
$$

where

$\lambda$ is the relative radiation reflectivity of the surface of the liquid,

$\varepsilon_{\text {sky }}=1$ because the sky acts as an absolute black body [1],

$T_{\text {sky }}$ is the surface temperature of the radiating "body" [K].

The previous approximate relationship covers only cloud cover, while other atmospheric characteristics can also influence the intensity of longwave rewind. In addition to cloud cover, cloud height, quality, air composition, especially concentration of green-house gases, partial vapour pressure, smoke, fog, etc. [3-5] also affect the intensity of longwave rewind.

For a significant part of the related publications, it is therefore proposed to introduce an atmospheric radiation factor $(\beta)$, which is characteristic of the "composition" of the current atmosphere [1-3]. The $\beta$ varies between 0.75 and 0.95 intervals [1] under most meteorological and environmental conditions. The heat flux density absorbed by the ambient air and absorbed by the liquid surface can thus be estimated by the relation (5) [1]:

$$
Q_{\text {rew. }}=(1-\lambda) \beta \sigma\left(T_{\text {air }}+273\right)^{4}
$$

where

$\lambda$ is the flow. (0.03),

$\beta$ Atmospheric Radiation Factor (0.75-0.95) [1], $T_{\text {air }}$. ambient air temperature $\left[{ }^{\circ} \mathrm{C}\right]$.

\section{The complete electromagnetic radia- tion balance}

In the examined system, members of the pool (heat radiation, atmospheric radiation), a component of the heat loss (atmospheric radiation), are considered negative (6).

$$
Q_{\text {st }}=Q_{s}+Q_{\text {rew. }}-Q_{\text {out }}=Q_{s}-Q_{A}
$$

\section{Results}

Based on the above (1) - (6) relationships (complex point system equations without completeness), model calculations can be performed on the specific $1 \mathrm{~m}^{2}$ liquid surface. 
The values of the most important parameters for calculation are: $\sigma$ Stefan-Boltzmann constant $\left[5.67 * 10-8 \mathrm{~W} / \mathrm{m}^{2} / \mathrm{K}^{4}\right], \varepsilon_{\text {flow }}$. The relative emission of the surface of the liquid [0.97], $\lambda$ is based on the relative radiation reflectivity of the sewage surface [0.03], $\beta$ atmospheric radiation factor [0.75].

The presented model of this paper calculates the total electromagnetic radiation balance of surfaces for 10,16 and $20^{\circ} \mathrm{C}$, by taking into account the different meteorological data of Hungary.

The obtained result of the model is shown in

\section{Figure 1.}

The estimated values quantify the effects of atmospheric electromagnetic radiation on open systems. Figure 1. shows the heat loss and surplus expected to be generated according to the seasons, what needs to take account. Increasing the complexity of the model (heat transfer, liquid heat evaporation, aeration heat, reaction heat, wall heat currents, and mechanical heat flow) can be suitable for describing the heat flow of the system to an appropriate level in order to explore the energv integration possibilities.

\section{Acknowledgements}

This research was supported by the European Union and the State of Hungary, cofinanced by the European Social Fund in the framework of TÁMOP 4.2.4. A/211-1-2012-0001 'National Excellence Program'. Also thanks for the support for GINOP-2.3.2-15-2016-00053 and GINOP-2.3.2-15-2016-00016 projects.

\section{References}

[1] Talati S. N., Stenstrom M. K.: Aeration-Basin Heat Loss. Journal of Environmental Engineering, 116/1. (1990) 70-87.

https://doi.org/10.1061/(ASCE) 0733 9372(1990)116:1(70)

[2] Jacobs A. F. G., Heusinkveld B. G., Berkowicz S. M.: Passive dew collection in a grassland area, the Netherlands. Atmospheric Research. 87. (2008) 377-385.

[3] Kiehl J. T., Trenberth K.E.: Earth's Annual Global Mean Energy Budget. Bulletin of American Meteorological Society. 78. (1997) 197-208.

[4] Mészáros R., Horváth L., Weidinger T., Neftel A., Nemitz E., Dämmgen U., Cellier P., Loubet B.: Measurement and modelling ozone fluxes over a cut and fertilized grassland. Biogeosciences 6 . (2009) 1987-1999.

https://doi.org/10.5194/bg-6-1987-2009

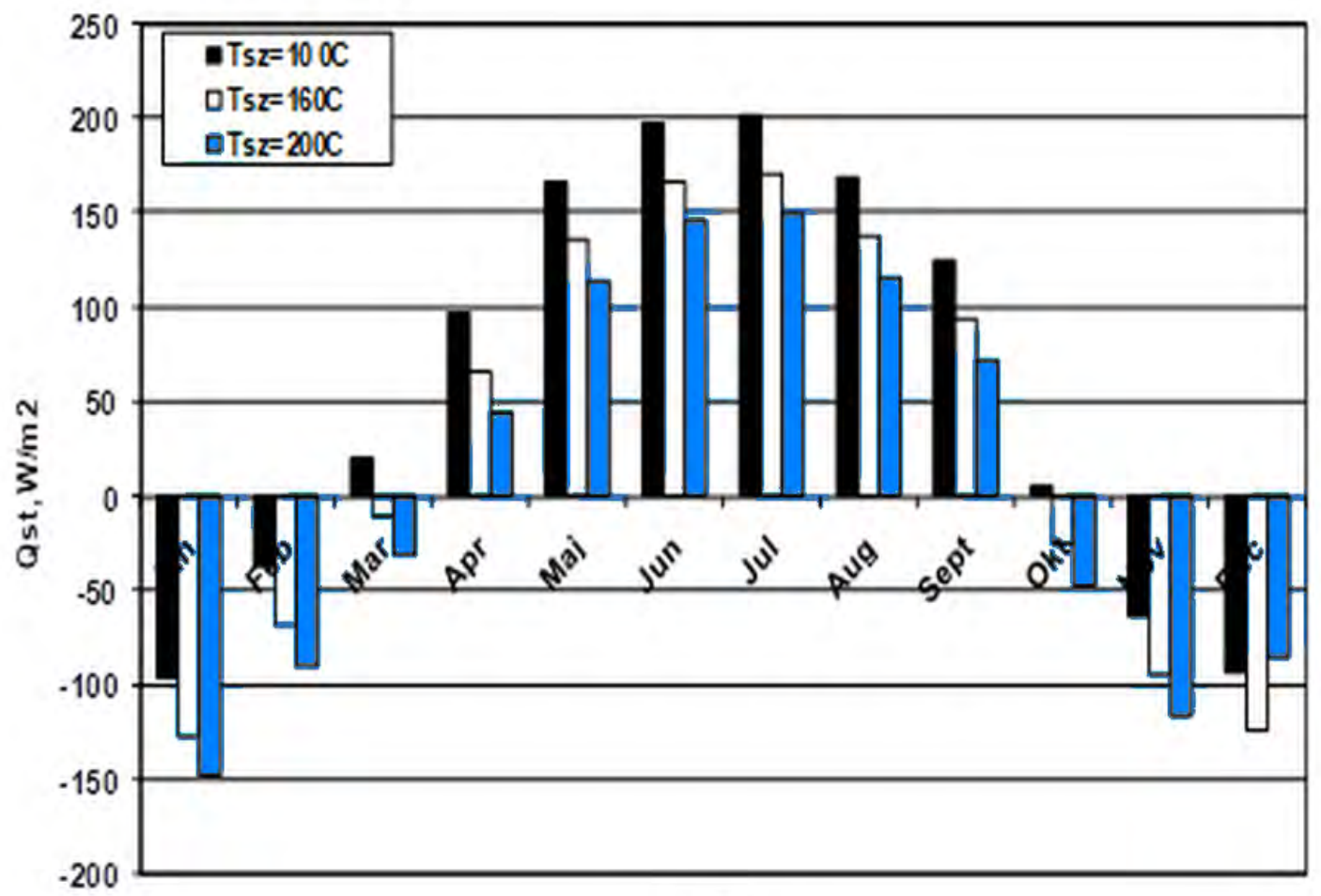

month

Figure 1. Total Radiation Balance, Monthly Average Data, $T=10,16$ and 20 oC and $\beta=0.75$ 
[5] Mileta M., Beyens,D., Nikolayev V., Milimouk I., Clus O., Muselli, M.: Fog and Dew Collection Projects in Crotia. Proc. International Conference on "Water Observation and Information System for Decision Support”. (BALWOIS 2006), Ohrid, Republic of Macedonia, 23-26 May 2006.

[6] Argyelán J.: Transzportfolyamatok. Pannon Egyetemi Kiadó, Veszprém, 2009. 159-174.

[7] H. Faltin: Müszaki hőtan. Műszaki Könyvkiadó, Budapest, 1970. 342-357. 